\title{
Inhibition of phospholipid and platelet-dependent prothrombinase activity in the plasma of patients with lupus anticoagulants
}

Citation for published version (APA):

Galli, M., Beguin, S., Lindhout, T., \& Hemker, C. H. (1989). Inhibition of phospholipid and plateletdependent prothrombinase activity in the plasma of patients with lupus anticoagulants. British Journal of Haematology, 72(4), 549-555. https://doi.org/10.1111/j.1365-2141.1989.tb04322.x

Document status and date:

Published: 01/08/1989

DOI:

10.1111/j.1365-2141.1989.tb04322.x

Document Version:

Publisher's PDF, also known as Version of record

Please check the document version of this publication:

- A submitted manuscript is the version of the article upon submission and before peer-review. There can be important differences between the submitted version and the official published version of record.

People interested in the research are advised to contact the author for the final version of the publication, or visit the DOI to the publisher's website.

- The final author version and the galley proof are versions of the publication after peer review.

- The final published version features the final layout of the paper including the volume, issue and page numbers.

Link to publication

\footnotetext{
General rights rights.

- You may freely distribute the URL identifying the publication in the public portal. please follow below link for the End User Agreement:

www.umlib.nl/taverne-license

Take down policy

If you believe that this document breaches copyright please contact us at:

repository@maastrichtuniversity.nl

providing details and we will investigate your claim.
}

Copyright and moral rights for the publications made accessible in the public portal are retained by the authors and/or other copyright owners and it is a condition of accessing publications that users recognise and abide by the legal requirements associated with these

- Users may download and print one copy of any publication from the public portal for the purpose of private study or research.

- You may not further distribute the material or use it for any profit-making activity or commercial gain

If the publication is distributed under the terms of Article 25fa of the Dutch Copyright Act, indicated by the "Taverne" license above, 


\title{
Inhibition of phospholipid and platelet-dependent prothrombinase activity in the plasma of patients
} with lupus anticoagulants

\author{
Monica Galli, Suzette Béguin, Theo Lindhout and Coenraad H. Hemker University of Limburg, \\ Department of Biochemistry, Maastricht, The Netherlands
}

Received 16 December 1988; accepted for publication 30 March 1989

Summary. Prothrombinase activity was analysed in the plasma of a series of patients with lupus anticoagulants (LAC). In the presence of purified PS-PC (20-80\%) vesicles the prothrombinase activity triggered by kaolin was retarded by $2-3$ min with respect with normal plasma. The maximal values of prothrombinase activity increased by increasing the amount of phospholipid vesicles. However, in the plasma of the patients they were always lower than those of normal plasma at each phospholipid concentration. Platelet-dependent prothrombinase activity was subsequently investigated. Again, both a delay in appearance and reduced peak values of prothrombinase activity were observed in the plasma of the patients. This inhibition was partially overcome by the addition of an excess of purified phospholipids. Finally, the effect of LAC IgG on platelet rich plasma-dependent prothrombinase activity was investigated. The main effect observed was a delay of the peak time of prothrombinase activity, while the maximal peaks were affected only by one IgG preparation. We conclude that LAC antibodies can react with both purified negatively-charged phospholipids and platelet procoagulant phospholipids and inhibit prothrombinase activity in a similar way in both cases.
Lupus anticoagulants (LAC) are acquired inhibitors of coagulation described for the first time in 1952 by Conley \& Hartmann in two patients suffering from systemic lupus erythematosus (SLE).

LAC are immunoglobulins of the IgG and/or (less frequently) IgM class, which prolong the clotting tests measuring the activated partial thromboplastin time (aPTT) (Mueh et al, 1980).

The immunological nature and the mechanism of action of LAC have been extensively studied by the group of Shapiro (Thiagarajan et al, 1980; Pengo et al, 1987). The purified immunoglobulins react against negatively-charged phospholipids (i.e. phosphatidylserine, phosphatidic acid, phosphatidylinositol and cardiolipin) and they are able to inhibit the binding of factor $\mathrm{X}$ and prothrombin to the phospholipid surface, thereby accounting for the prolongation of phospholipid-dependent clotting tests.

Phospholipids are structural components of the platelet membrane. The negatively-charged phospholipids are almost exclusively located in the inner part of the membrane of

Correspondence: Dr Monica Galli, Department of Haematology, Ospedali Riunití, Largo Barozzi 1, 24100 Bergamo, Italy. resting platelets, but they are exposed on the outer surface upon platelet activation (Bevers et al, 1982). This transbilayer rearrangement has been called 'flip-flop' and is responsible for the procoagulant properties of platelets in factor $\mathrm{X}$ and prothrombin activation (Rosing et al, 1985). It seems to be likely that LAC antibodies, by binding to the negativelycharged phospholipids, can interfere with the procoagulant activity of activated platelets. Actually, this has been demonstrated only in one case by Dahlback et al (1983), while in their original work Thiagarajan et al (1980) were not able to show any inhibitory effect of the LAC immunoglobulin on the binding of factor Xa to platelets. Furthermore, other authors developed assays for the diagnosis of LAC, based on the ability of platelets to normalize the prolonged clotting tests (Firkin $e t$ al, 1978; Triplett et al, 1983). Thus, it was suggested that platelets can by-pass the presence of the acquired anticoagulants. In contrast, it has been suggested that LAC antibodies can react with platelets, because thrombocytopenia (Harris et al, 1985), 'ex vivo' platelet activation (Galli et al, 1988) and 'in vitro' platelet aggregation abnormalities (Cohen et al, 1986) have been reported in patients with the antiphospholipid antibodies. Moreover, it has been observed that commercially available phospholipid reagents for clotting tests, used to detect LAC inhibitors, show a large variation of sensitivity to 
the antibodies due to the variations in both the concentrations and the nature of the phospholipid in the preparation (Mannucci et al, 1979). These data led to the hypothesis that LAC antibodies are heterogenous.

To assess whether there is a general reactivity of LAC immunoglobulins towards negatively-charged phospholipids from different sources, we studied the plasma of a series of patients with these antibodies. In particular, we evaluated the inhibitory effect of the acquired anticoagulants on the prothrombinase activity induced by platelets and by purified negatively-charged phospholipids vesicles. We used a computer assisted method, recently developed in this laboratory (Hemker et al, 1986), which allowed us to measure the prothrombinase activity in plasma independently of thrombin breakdown by antiproteases. Thus, we could approach closely the 'in vivo' situation. We demonstrate here that the inhibition of prothrombinase activity by LAC antibodies is more dependent on the amount of negatively-charged phospholipids present in the system than on the source of procoagulant surface.

\section{MATERIALS AND METHODS}

Patients. Nine patients with LAC were investigated, two males and seven females, 27-60 years old. Details of the clinical history are given in Table I. SLE was diagnosed according to the criteria established by the American Rheumatism Association (Tan et al, 1982). Both venous and arterial thrombosis were diagnosed by angiography.

A control group was established of 10 apparently healthy subjects.

Diagnosis of LAC. Blood was collected in trisodium citrate (9 volumes of blood to 1 volume of $0.13 \mathrm{M}$ trisodium citrate) and centrifuged at $4000 \mathrm{~g}$ for $20 \mathrm{~min}$ to obtain platelet poor plasma (PPP). PPP was stored at $-80^{\circ} \mathrm{C}$ until use. Plasma of 10 normal individuals was pooled and used as a reference in the coagulation assays. The following tests were used for the diagnosis of LAC: activated partial thromboplastin time (aPTT) (Activated Thrombofax, Ortho Diagnostic, Raritan, N.J., U.S.A.), kaolin clotting time (KCT) (Exner et al, 1978) and diluted Russel viper venom time (RVV) (Thiagarajan et al, 1986) (Wellcome Reagents Beckenam, England), before and after $1: 1$ mixture of patients plasma with normal pooled plasma, tissue thromboplastin inhibition test (TTI), using Simplastin (General Diagnostics, Warner Lambert Co., Morris Plains, N.J., U.S.A.) diluted 1:50 and 1:500 with saline (Schleider et al, 1976).

Preparation of IgG immunoglobulins. IgG immunoglobulins from seven patients and four normal subjects were isolated. Serum (20 ml) was dialysed against $0.02 \mathrm{M} \mathrm{K}_{2} \mathrm{HPO}_{4}, \mathrm{pH} 8 \cdot 0$ at $4^{\circ} \mathrm{C}$ overnight. Then it was applied to a column of DEAE Aff-Gel Blue (Bio Rad, Richmond, Calif, U.S.A.) equilibrated with the same buffer. The effluent immunoglobulins were concentrated by Amicon ultrafiltration, using a PM 10 membrane (Amicon Corp, Lexington, Mass., U.S.A.). Protein concentration was established by a nephelometric method using a Beckman system (Auto ICS, Beckman Instr., Fullerton, Calif., U.S.A.). Immunoelectrophoresis was performed with human antisera specific for total immunoglobulins, IgG,
IgM and light chains (Helèna Laboratories, Beaumont, Texas, U.S.A.).

Patients IgG were studied for their anticoagulant activity by adding $0.05 \mathrm{ml}$ of IgG to $0.05 \mathrm{ml}$ of normal pooled PPP in a KCT assay. Anticoagulant activity was considered to be present, when the clotting time was at least 1.5 times that of the control, i.e. with IgG from normal subjects.

Measurement of prothrombinase activity in plasma. For the measurement prothrombinase activity in plasma the procedure of Hemker et al (1986) was used. Briefly, $0 \cdot 24 \mathrm{ml}$ of normal pooled or patients PPP were incubated at $37^{\circ} \mathrm{C}$ for 5 min with $0.06 \mathrm{ml}$ of Tris buffer $(0.1 \mathrm{M} \mathrm{NaCl}, 0.05 \mathrm{M}$ Tris, $\mathrm{pH}$ $7 \cdot 35)$ containing kaolin $(0 \cdot 28 \mathrm{mg} / \mathrm{ml})$ and various concentrations of phospholipid vesicles ( $80 \%$ phosphatidylcholine, PC, and $20 \%$ of phosphatidylserine, PS), prepared according to Rosing et al (1983) or with $0.06 \mathrm{ml}$ of different concentrations of washed platelet suspensions, prepared according to Rosing et al (1985). In some experiments, $40 \mu \mathrm{M}$ of purified PS/PC vesicles were added to PPP at the same time as the washed platelets. Thrombin generation was started by the addition of $0.06 \mathrm{ml}$ of $0.1 \mathrm{M} \mathrm{CaCl}_{2}, \mathrm{pH} 7 \cdot 35$. At fixed time intervals $0.01 \mathrm{ml}$ aliquots of the incubation mixture were subsampled into tubes containing $0.465 \mathrm{ml}$ of a Tris-EDTA buffer $(0.1 \mathrm{M} \mathrm{NaCl}, 0.05 \mathrm{~m}$ Tris, $0.02 \mathrm{M} \mathrm{EDTA,} 0.05 \%$ ovalbumin, $\mathrm{pH} 7.9$ ) and $0.025 \mathrm{ml}$ of a $0.004 \mathrm{M}$ solution of chromogenic substrate S2238 (Kabi Vitrum, Stockholm, Sweden) at $37^{\circ} \mathrm{C}$. The subsampling tubes were incubated for $2 \mathrm{~min}$ at $37^{\circ} \mathrm{C}$ and then, by addition of $0.3 \mathrm{ml}$ of $50 \%$ acetic acid, the reaction was stopped. The amidolytic activity was measured at $405 \mathrm{~nm}$ wavelength in a spectrophotometer (LKB-Ultrospec., Bromma, Sweden). From the change in absorbance and the time interval between subsampling and stopping the thrombin amidolytic activity was calculated. Thrombin concentration was calculated using a calibration curve made with active-site titrated human thrombin.

Thrombin breakdown constants were also determined according to Hemker et al (1986). Briefly, the same mixture as for thrombin generation curves was used, but with a volume of $0.048 \mathrm{ml}$ of Tris-buffer mixture or platelet suspension instead of $0.06 \mathrm{ml}$. Two minutes after the thrombin peak $0.012 \mathrm{ml}$ of Soybean trypsin inhibitor (SBTI) $(10 \mathrm{mg} / \mathrm{ml}$ ) (Sigma, St Louis, Mass., U.S.A.) were added to the reaction mixture, so as to stop prothrombinase activity. At variable intervals after the addition of SBTI, $0.01 \mathrm{ml}$ aliquots were subsampled into cuvettes by the use of a time recording pipette. The cuvettes were further treated as described for the thrombin generation test. The overall decay constant is the sum of the $\alpha_{2}$ macroglobulin $\left(\alpha_{2} \mathrm{M}\right)$ dependent constant $\left(k_{2}\right)$ and the non- $\alpha_{2} \mathrm{M}$-dependent constant $\left(k_{1}\right)$, mainly due to antithrombin III. From the ratio of the amount of prothrombin consumed during the experiment (i.e. the total amount of thrombin formed) and the amount taken up by $\alpha_{2} M$, determined using staphylocoagulase $(50 \mathrm{~nm}$ ) (Hendrix et al, 1983), $k_{1}$ and $k_{2}$ were determined separately (for details see Hemker et al, 1986).

Prothrombinase activity (expressed in $\mathrm{nM} \mathrm{\Pi a} / \mathrm{min}$ ) was calculated by a computer using the thrombin generation data and the experimentally determined decay constants $k_{1}$ and $k_{2}$ of endogenous thrombin (Hemker et al, 1986). 
Table I. Clinical and laboratory data in nine patients with LAC

\begin{tabular}{|c|c|c|c|c|c|c|c|c|c|c|c|c|}
\hline \multirow[b]{2}{*}{ Patient } & \multirow{2}{*}{ Age } & \multirow{2}{*}{ Sex } & \multirow[b]{2}{*}{ Clinical remarks } & \multirow[b]{2}{*}{ APTT } & \multirow[b]{2}{*}{ APTT 1: 1} & \multirow[b]{2}{*}{ KCT } & \multirow[b]{2}{*}{ KCT $1: 1$} & \multicolumn{2}{|l|}{ TTI } & \multirow[b]{2}{*}{ RVV } & \multirow{2}{*}{ RVV $1: 1$} & \multirow{2}{*}{$\begin{array}{l}\text { Type of } \\
\text { LAC } \\
\text { antibody }\end{array}$} \\
\hline & & & & & & & & $1 / 50$ & $1 / 500$ & & & \\
\hline R.A. & 30 & $\mathrm{~F}$ & $\begin{array}{l}\text { SLE; transient } \\
\text { ischaemic attacks }\end{array}$ & 46 & 35 & 186 & 168 & 60 & 119 & 52 & 46 & 一 \\
\hline G.S. & 33 & M & $\begin{array}{l}\text { Peripheral arterial } \\
\text { thrombosis }\end{array}$ & 36 & 36 & 98 & 96 & 50 & 98 & 60 & 49 & IgG \\
\hline C.L. & 27 & F & $\begin{array}{l}\text { Recurrent abortions; } \\
\text { deep venous thrombosis }\end{array}$ & 46 & 37 & 178 & 126 & 54 & 109 & 73 & & IgG \\
\hline D.S. & 31 & $\mathrm{~F}$ & SLE & 40 & - & 196 & - & 61 & 151 & - & - & IgG \\
\hline M.S. & 60 & M & Deep venous thrombosis & 48 & 36 & 130 & 113 & 102 & 252 & 65 & 48 & - \\
\hline Z.R. & 41 & $\mathrm{~F}$ & Cerebral thrombosis & 35 & 34 & 109 & 111 & 43 & 85 & 63 & - & IgG \\
\hline T.A. & 29 & $\mathrm{~F}$ & Repeated abortions; SLE & 75 & 66 & 110 & 97 & 59 & 132 & 41 & 38 & $\operatorname{IgG}$ \\
\hline T.N. & 36 & $\mathrm{~F}$ & Repeated abortions; SLE & 34 & 30 & 127 & 100 & - & - & - & - & IgG \\
\hline B.A. & 56 & $\mathrm{~F}$ & - & 60 & 43 & 140 & 121 & - & - & - & - & IgG \\
\hline Controls (10) & & & & $26-30$ & & $64-75$ & & $35-40$ & $63-77$ & $25-30$ & & \\
\hline
\end{tabular}

All results are expressed in seconds.

Effect of LAC IgG on prothrombinase activity in normal platelet rich plasma. Platelet rich plasma (PRP) was obtained by centrifugation at $170 \mathrm{~g}$ for $10 \mathrm{~min}$ of freshly drawn citrated normal blood. Platelet concentration was determined with a thrombocounter (Coulter Counter Electronics, Hialeah, Fla., U.S.A.) and adjusted at $300 \times 10^{9}$ platelets $/ 1$ with autologous PPP.

Thrombin generation and prothrombinase activity were determined according to the method of Béguin et al (1989). The samples consisted of $0.24 \mathrm{ml}$ of PRP and $0.06 \mathrm{ml}$ of normal pooled or patients $\mathrm{IgG}$ at various concentrations. After $5 \mathrm{~min}$ of incubation at $37^{\circ} \mathrm{C}$ the thrombin generation was started by the addition of $0.06 \mathrm{ml}$ of $0.1 \mathrm{M} \mathrm{CaCl}_{2}$ or 0.06 ml of a $1: 600$ dilution in $0.1 \mathrm{M} \mathrm{CaCl}_{2}$ of human brain thromboplastin, prepared by a modification of the method of Owren \& Aas (1951) and prewarmed for $1 \mathrm{~h}$ at $37^{\circ} \mathrm{C}$. At fixed time intervals $0.01 \mathrm{ml}$ aliquots of the incubation mixture were subsampled into tubes containing $0.465 \mathrm{ml}$ of TrisEDTA buffer and $0.025 \mathrm{ml}$ of a $0.004 \mathrm{M}$ solution of $\mathrm{S} 2238$ at $37^{\circ} \mathrm{C}$. The subsampling tubes were incubated for $2 \mathrm{~min}$ at $37^{\circ} \mathrm{C}$ and then, by addition of $0.3 \mathrm{ml}$ of $50 \%$ acetic acid, the reaction was stopped. The amidolytic activity was tested as above described.

In order to overcome the effect of platelet ageing, the experiments were carried out within $2 \mathrm{~h}$ from the venipuncture. Prothrombinase activity was calculated as above described.

\section{RESULTS}

Coagulation studies and characterization of LAC inhibitors The aPTT, KCT and dilute RVV clotting times in all the nine patients exceeded those of the normal group and no correction was noted on mixing 1:1 patients and normal PPP. TTI was also abnormal in all the cases (Table I).

Immunoglobulins with LAC activity were found to be IgG in the seven patients in whom the identification of the inhibitor was performed (Table I).

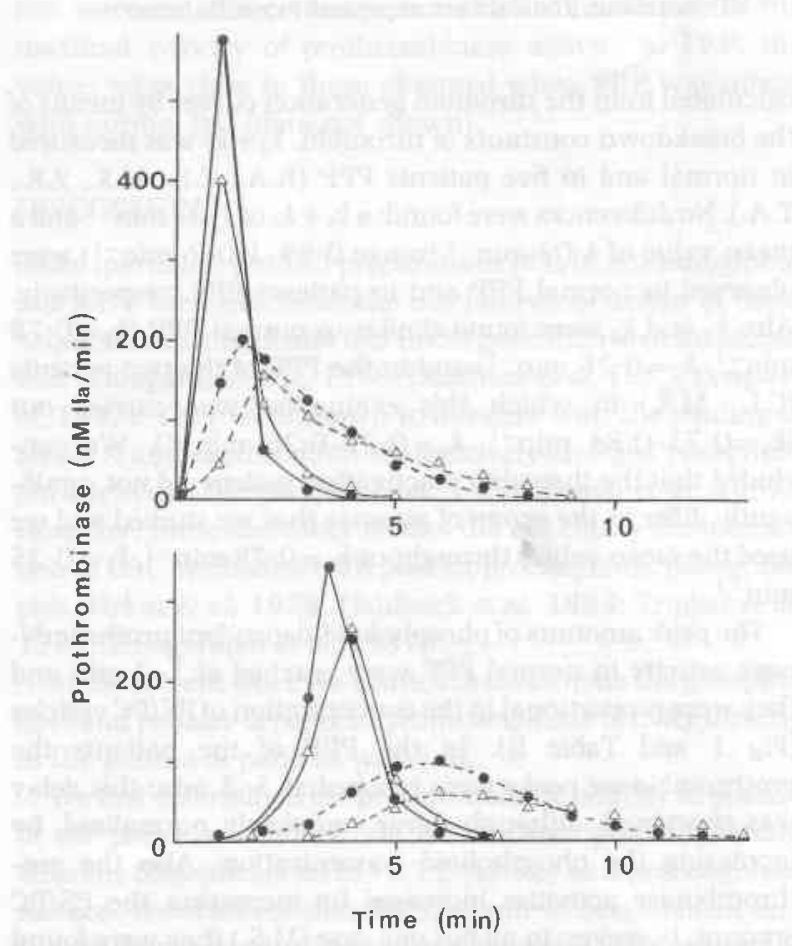

Fig 1. Prothrombinase activity ( $\mathrm{nm} \mathrm{IIa/min)} \mathrm{in} \mathrm{normal} \mathrm{pooled} \mathrm{plasma}$ (upper panel) and in the plasma of patient R.A. (lower panel) induced by the following concentrations of PS/PC vesicles: $\Delta-\cdots-\Delta, 0 \cdot 5 \mu \mathrm{M}$; $\bullet--1 \mu \mathrm{M} ; \Delta--\Delta, 5 \mu \mathrm{M} ; \bullet \bullet, 10 \mu \mathrm{M}$.

Effect of phospholipid vesicles and normal platelets on prothrombinase activity in PPP

Phospholipid-dependent prothrombinase activity was evaluated in normal and in eight patients' PPP. Reactions were studied in the intrinsic pathway, using procoagulant phospholipid vesicles (PS/PC) at the concentrations given in Fig 1 and Table II. The course of prothrombinase activity was 
Table II. Maximal amounts of prothrombinase activities in patients and normal pooled PPP in the presence of phospholipid vesicles or washed normal platelets

\begin{tabular}{|c|c|c|c|c|c|c|}
\hline \multirow{2}{*}{ Patient } & \multicolumn{4}{|c|}{$\mathrm{PS} / \mathrm{PC}(\mu \mathrm{M})$} & \multicolumn{2}{|c|}{$\begin{array}{l}\text { Washed } \\
\text { platelets } \\
\left(\times 10^{9} / 1\right)\end{array}$} \\
\hline & 0.5 & 1 & 5 & 10 & 100 & 200 \\
\hline R.A. & 65 & 95 & 251 & 310 & 44 & 53 \\
\hline G.S. & $\mathrm{ND}^{*}$ & 113 & 152 & ND & 37 & 64 \\
\hline C.L. & 76 & 115 & 348 & 415 & 53 & 62 \\
\hline D.S. & 104 & 117 & 316 & 352 & 55 & 75 \\
\hline M.S. & 109 & 204 & 463 & ND & 61 & 104 \\
\hline Z.R. & 65 & 97 & 305 & 397 & 52 & 85 \\
\hline T.A. & 73 & 123 & 306 & 384 & 65 & 80 \\
\hline T.N. & $\mathrm{ND}$ & ND & ND & ND & ND & ND \\
\hline B.A. & ND & 28 & 54 & 73 & 9 & 20 \\
\hline $\begin{array}{l}\text { Normal } \\
\text { pooled PPP }\end{array}$ & 119 & 200 & 433 & 538 & 81 & 91 \\
\hline
\end{tabular}

${ }^{*} \mathrm{ND}$ : not done. The data are expressed in $\mathrm{nm} \mathrm{IIa/min.}$

calculated from the thrombin generation curves by means of the breakdown constants of thrombin. $k_{1}+k_{2}$ was measured in normal and in five patients PPP (R.A., C.L., M.S., Z.R., T.A.). No differences were found: $\mathrm{a} k_{1}+k_{2}$ of $1.04 \mathrm{~min}^{-1}$ and a mean value of $1.03 \mathrm{~min}^{-1}$ (range $0.99-1.066 \mathrm{~min}^{-1}$ ) were observed in normal PPP and in patients PPP, respectively. Also $k_{1}$ and $k_{2}$ were found similar in normal PPP $\left(k_{1}=0 \cdot 78\right.$ $\min ^{-1}, k_{2}=0 \cdot 26 \mathrm{~min}^{-1}$ ) and in the PPP of the two patients (C.L., M.S.) in which this evaluation was carried out $\left(k_{1}=0 \cdot 73-0.84 \mathrm{~min}^{-1}, k_{2}=0 \cdot 22-0 \cdot 26 \mathrm{~min}^{-1}\right)$. We concluded that the thrombin inactivation system did not significantly differ in the group of plasmas that we studied and we used the mean values throughout $k_{1}=0 \cdot 78 \mathrm{~min}^{-1}, k_{2}=0 \cdot 25$ $\min ^{-1}$.

The peak amounts of phospholipid-dependent prothrombinase activity in normal PPP were reached at $1-2 \mathrm{~min}$ and they were proportional to the concentration of PS/PC vesicles (Fig 1 and Table II). In the PPP of the patients the prothrombinase peaks were reached at 5-3 min: this delay was shortened, although never completely normalized, by increasing the phospholipid concentration. Also the prothrombinase activities increased by increasing the PS/PC amount; however, in all but one case (M.S.) they were found lower than that of the normal PPP at each phospholipid value (Fig 1 and Table II).

In order to assess differences in the reactivity of LAC inhibitors towards phospholipids of different sources, the prothrombinase activity was subsequently evaluated in the presence of normal platelets as the source of procoagulant phospholipids. The prothrombinase activity was calculated from the thrombin generation data by means of the breakdown constants of thrombin. As a control, $k_{1}$ and $k_{2}$ were measured in normal PPP, PRP and reconstituted PRP (washed platelets resuspended in autologous PPP at a final number of $\left.200 \times 10^{9} / 1\right)$. As depicted in Table III, the values of
Table III. Thrombin breakdown constants of normal platelet poor plasma (PPP), platelet rich plasma (PRP) and reconstituted PRP. $k_{2}$ is the $\alpha_{2}$ macroglobulin dependent constant, $k_{1}$ the non $\alpha_{2}$ macroglobulin dependent constant.

\begin{tabular}{lll}
\hline & $\begin{array}{l}k_{2} \\
\left(\min ^{-1}\right)\end{array}$ & $\begin{array}{l}k_{1} \\
\left(\min ^{-1}\right)\end{array}$ \\
\hline PPP & $0 \cdot 13$ & 0.78 \\
PRP & $0 \cdot 13$ & $0 \cdot 85$ \\
Reconstituted PRP* & 0.13 & 0.88 \\
\hline
\end{tabular}

* Washed platelets resuspended in autologous PPP at a final concentration of $200 \times 10^{9} / \mathrm{l}$.

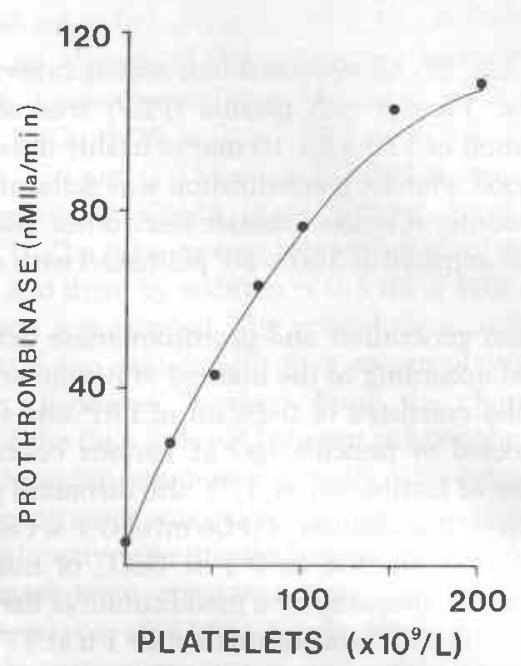

Fig 2. Concentration effect of washed normal platelets on the prothrombinase activity (nM IIa/min) in normal pooled plasma.

thrombin breakdown constants were not influenced by the presence of platelets. Thus, the values of $k_{1}$ and $k_{2}$ measured in PPP were also used to calculate platelet-dependent prothrombinase activity. A calibration curve was obtained by incubating normal PPP with increasing concentrations of washed platelets (from 0 to $200 \times 10^{9} / \mathrm{l}$ ). As depicted in Fig 2, prothrombinase activity increased with the platelet number.

Platelet-dependent prothrombinase activity in normal and eight patients' PPP was subsequently evaluated in the presence of 100 and $200 \times 10^{9}$ platelets/l. Clotting reactions were started by the addition of $\mathrm{CaCl}_{2}$. In these conditions the maximal prothrombinase activity was reached after 8-11 min with both 100 and $200 \times 10^{9}$ platelets $/ 1$ in normal PPP (Fig 3). Also the peak amount of prothrombinase activity did not change significantly with the number of platelets (Table II).

In the plasma of the patients the maximal amounts of 


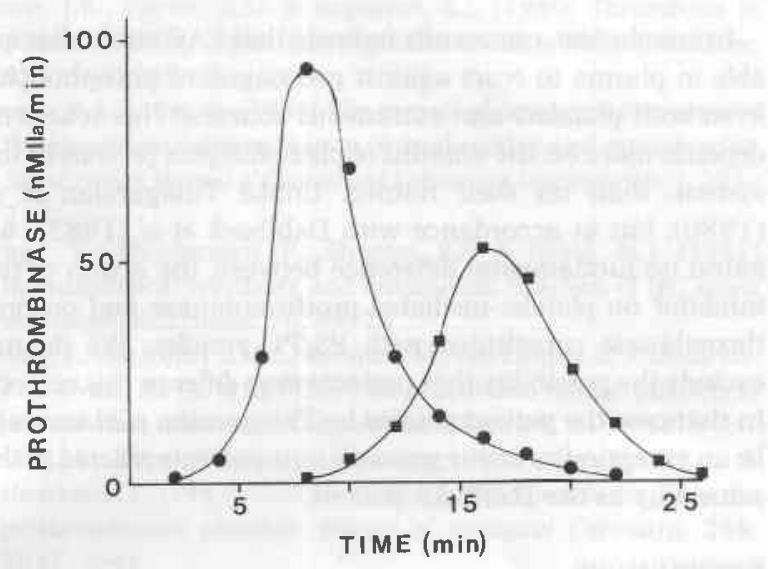

Fig 3. Prothrombinase activity ( $\mathrm{nM} \Pi \mathrm{a} / \mathrm{min}$ ) induced by $200 \times 10^{9}$ washed normal platelet/l in normal pooled plasma ( ) and in the plasma of patient R.A. (a).

prothrombinase activity were reached later and they were found lower than in normal plasma. The differences were more pronounced in the presence of $100 \times 10^{9}$ platelets $/ \mathrm{l}$. In particular, the peak amounts of prothrombinase activity were observed at $10-20 \mathrm{~min}$ with $100 \times 10^{9}$ platelets $/ \mathrm{l}$ and at 9-16 min in the presence of $200 \times 10^{9}$ platelets $/$. The values of prothrombinase are given in Table II. When an excess of PS/PC vesicles ( $40 \mu \mathrm{M})$ was added at the same time as $100 \times 10^{9}$ washed platelets/l to the plasmas of three patients (R.A., G.S., B.A.) prothrombinase activity was completely normalized in two cases (R.A., G.S.) and partially normalized in the third one (patient B.A.) (data not shown).

\section{Effect of LAC IgG on prothrombinase activity in normal PRP}

The maximal prothrombinase activity was reached at 8-11 min when normal PRP was mixed with $10 \mathrm{mg} / \mathrm{ml}$ of normal pooled IgG and coagulation was initiated by the addition of $\mathrm{CaCl}_{2}$. The peak value of prothrombinase activity was advanced to 6-8 $\mathrm{min}$ in the presence of a high dilution of thromboplastin (1:3600 final). No significant differences were found in the maximal prothrombinase activity in these two experiments. In fact, the mean values were $114 \mathrm{~nm}$ IIa $\mathrm{min}^{-1}$ (range 94-152) and $95 \mathrm{~nm} \mathrm{Ila} \mathrm{min}^{-1}$ (range 80-124) in the presence of $\mathrm{CaCl}_{2}$ and calcium plus thromboplastin, respectively. The main effect exerted by LAC IgG on normal PRP was a delay of the peak time of prothrombinase activity. When the clotting reaction was started by $\mathrm{CaCl}_{2}$ the peak was reached at 11-18 $\mathrm{min}$. In the presence of thromboplastin the delay was reduced in all cases (range 4-15 min) and completely normalized in two of them (patients C.L. and Z.R.). These results were obtained using $10 \mathrm{mg} / \mathrm{ml}$ of IgG with LAC activity. In one case only (patient B.A.) concentrations of IgG higher than $1 \mathrm{mg} / \mathrm{ml}$ completely abolished the prothrombinase activity. From Fig 4 it appears that the peak amount was reduced and the lag time was increased by increasing amounts of this patient's IgG. In the other cases the delay of the peak time of prothrombinase activity was almost completely normalized when the concentration of LAC IgG was decreased to $5 \mathrm{mg} / \mathrm{ml}$ (data not shown). LAC immunoglobu-

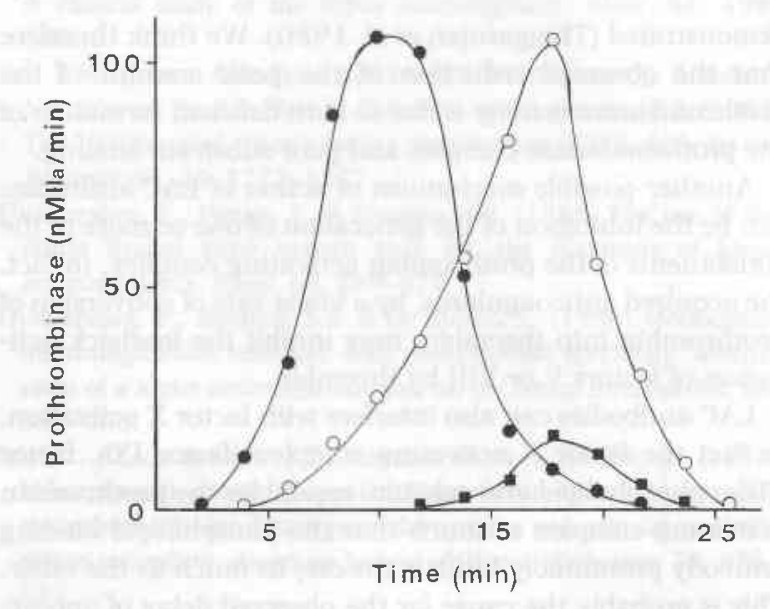

Fig 4. Prothrombinase activity ( $\mathrm{nM} \mathrm{IIa} / \mathrm{min}$ ) in platelet-rich plasma in the presence of normal and LAC IgG. - Normal IgG

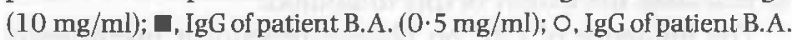
$(0 \cdot 1 \mathrm{mg} / \mathrm{ml})$.

lins were, on the contrary, not able to interfere with the maximal velocity of prothrombinase activity in PRP: the values were close to those observed when PRP was mixed with normal IgG (data not shown).

\section{DISCUSSION}

Since (partially) purified preparations of LAC immunoglobulins have been available, the mechanism of action of these acquired anticoagulants has undergone intensive investigation (Thiagarajan et al, 1980; Dahlback et al, 1983; Pengo et al, 1987). They were shown to interfere with the binding of factor $\mathrm{X}$ and prothrombin to negatively-charged phospholipid surfaces (Thiagarajan et al, 1980; Pengo et al, 1987). However, these and other studies did not clarify the interaction of LAC antibodies with platelet procoagulant phospholipids (Firkin et al, 1978; Dahlback et al, 1983; Triplett et al, 1983; Thiagarajan et al, 1987).

In the present work we wanted to investigate the phospholipid and platelet-dependent prothrombinase activity directly in the plasma of patients with LAC.

We first determined the prothrombinase activity in plasma of the patients activated via the intrinsic pathway, using different concentrations of PS/PC vesicles as a procoagulant surface. We observed that both the rate of development and the peak amount of prothrombinase activity were reduced in the plasma of the patients. This phenomenon was clearly dependent on the amount of phospholipid in the system, since a partial normalization of the prothrombinase activity was reached by increasing the concentration of $\mathrm{PS} / \mathrm{PC}$ vesicles.

By binding to the phospholipid surface, LAC antibodies may inhibit the prothrombinase activity by hampering the assembly of the prothrombin activating complex (factor Xa, factor Va, phospholipid and calcium) on the procoagulant surface or by hindering the binding of prothrombin to an otherwise normal prothrombinase complex. The interference of LAC immunoglobulins with the binding of factor Xa and prothrombin to purified phospholipids has already been 
demonstrated (Thiagarajan et al, 1980). We think therefore that the observed reduction of the peak amount of the prothrombinase activity is due to both deficient formation of the prothrombinase complex and poor substrate binding.

Another possible mechanism of action of LAC antibodies can be the inhibition of the generation of one or more of the constituents of the prothrombin activating complex. In fact, the acquired anticoagulants, by a lower rate of conversion of prothrombin into thrombin, may inhibit the feedback activation of factors $\mathrm{V}$ or VIII by thrombin.

$\mathrm{LAC}$ antibodies can also interfere with factor $\mathrm{X}$ activation. In fact the factor $\mathrm{X}$ activating complex (factor IXa, factor VIIIa, phospholipid and calcium) resembles the prothrombin activating complex so much that the phospholipid binding antibody presumably inhibits the one as much as the other. This is probably the cause for the observed delay of appearance of the prothrombinase activity. Further studies will have to elucidate the extent of this inhibition.

The influence of LAC on platelet-dependent prothrombinase activity was also investigated. We demonstrated that platelets do not significantly influence the breakdown constants ( $k_{1}$ and $k_{2}$ ) of thrombin in plasma (see Table III). It has been observed that activated platelets increase the rate of thrombin inhibition by AT III (Jesty, 1985). We did not observe a significant effect. It is noteworthy that no platelet product responsible for the increase of thrombin inhibition has as yet been identified.

We found that prothrombinase activity was also affected in plasma of the patients when washed normal platelets were used as procoagulant surface. Recently, Béguin et al (1989) demonstrated the existence of a feedback activation of platelets by the small amounts of thrombin formed in PRP in the early stages of coagulation triggered by tiny amounts of thromboplastin; this makes platelet procoagulant phospholipids available to stimulate a burst of thrombin formation. LAC antibodies, by binding to the exposed negativelycharged platelet phospholipids, hamper this feedback activation, thus accounting for both the delay in the appearance and the reduction of the peak levels of the prothrombinase activity. As expected from the observed correlation between the number of platelets and prothrombinase activity (see Fig 2 ). this inhibition of platelet-dependent prothrombinase activity was more obvious at a low platelet number. Moreover, it was (partially) overcome by the addition of an excess of phospholipids, thus suggesting that the amount of negatively-charged phospholipid more than its source imports for the expression of the anticoagulant effect of LAC antibodies. The correlation observed in PRP between the delay of appearance of prothrombinase activity and the amount of LAC IgG in the presence of different triggers of platelet activation supports this view. Unlike the patients' plasma, the purified LAC immunoglobulins were not able to inhibit the maximal level of platelet-dependent prothrombinase activity. This difference might be due to a loss of specific antibodies during the purification procedure, since it had been found that polyclonal LAC IgG accounts for no more than the $0.2 \%$ of the whole IgG fractions (Pengo et al, 1987). Moreover protein(s) other than IgG might take part in the inhibitory process in the plasma of the patients (Exner et al, 1978).
In conclusion, our results indicate that LAC antibodies are able in plasma to react against procoagulant phospholipids from both platelets and extraneous sources. This reactivity depends more on the amount of phospholipids present in the system, than on their nature. Unlike Thiagarajan et al (1980), but in accordance with Dahlback et al (1983), we found no fundamental difference between the action of the inhibitor on platelet-mediated prothrombinase and on prothrombinase constituted with $\mathrm{PS} / \mathrm{PC}$ vesicles. We do not exclude the possibility that patients may differ in this respect. In that case the patient studied by Thiagarajan et al seems to be an exception as in our series all nine patients reacted in the same way as the Dahlback patient.

\section{REFERENCES}

Béguin, S., Lindhout, T. \& Hemker, H.C. (1989) The effect of trace amounts of tissue factor on thrombin generation in platelet rich plasma, its inhibition by heparin. Thrombosis and Haemostasis, 61, 25-29.

Bevers, E.M., Comfurius, P., van Rijn, J.L.M.L., Hemker, H.C. \& Zwaal, R.F.A. (1982) Generation of prothrombin converting activity and the exposure of phosphatidylserine at the outer surface of platelets. European Journal of Biochemistry, 122, 429436.

Cohen, A.J., Philips, T.M. \& Kessler, C.M. (1986) Circulating coagulation inhibitors in the acquired immunodeficiency syndrome. Annals of Internal Medicine, 104, 175-180.

Conley, C.L. \& Hartmann, R.C. (1952) A hemorrhagic disorder caused by circulating anticoagulant in patients with disseminated lupus erythematosus. Journal of Clinical Investigation. 31, 621622.

Dahlback, B., Nilsson, I.M. \& Frohm, B. (1983) Inhibition of prothrombinase activity by a lupus anticoagulant. Blood, 62, 218223.

Exner, T., Rickard, K.A. \& Kronenberg, H. (1978) A sensitive test demonstrating lupus anticoagulant and its behavioural pattern. British Journal of Haematology. 40, 143-151.

Firkin, B.G., Booth, P., Hendrix, L. \& Howard, M.A. (1978) Demonstration of a platelet bypass mechanism in the clotting system using an acquired anticoagulant. American Journal of Hematology. 5, 81-92.

Galli, M., Cortelazzo, S., Viero, P., Finazzi, G., de Gaetano, G. \& Barbui, T. (1988) Interaction between platelets and lupus anticoagulant. European Journal of Haematology, 41, 88-94.

Harris, E.N., Asherson, R.A., Gharavi, A.E., Morgan, S.H., Derue, G. \& Hughes, G.R.V. (1985) Thrombocytopenia in SLE and related autoimmune disorders-Association with anticardiolipin antibodies. British Journal of Haematology, 59, 227-230.

Hemker, H.C., Willems, G.M. \& Béguin, S. (1986) A computer assisted method to obtain the prothrombin activation velocity in whole plasma independently of thrombin decay processes. Thrombosis and Haemostasis, 56, 9-17.

Hendrix, H., Lindhout, T., Mertens, K., Engels, W. \& Hemker, H.C. (1983) Activation of human prothrombin by stoichiometric levels of staphylocoagulase. Journal of Biological Chemistry, 258, 36373644.

Jesty, J. (1985) The kinetics of inhibition of thrombin by antithrombin in the presence of components of hemostatic system. Blood, 66, 1189-1195.

Mannucci, P.M., Canciani, M.T., Mari, D. \& Menca, P. (1979) The varied sensitivity of partial thromboplastin and prothrombin time reagents in the demonstration of the lupus like anticoagulant. Scandinavian Journal of Haematology, 22, 423-432. 
Mueh, J.R., Herbst, K.D. \& Rapaport, S.I. (1980) Thrombosis in patients with the lupus anticoagulant. Annals of Internal Medicine, 92, 156-160.

Owren, P.A. \& Aas, K. (1951) The control of dicumarol therapy and the quantitative determination of prothrombin and proconvertin. Scandinavian Journal of Clinical and Laboratory Investigation, 3, 201218.

Pengo, V., Thiagarajan, P., Shapiro, S.S. \& Heine, M.J. (1987) Immunological specificity and mechanism of action of IgG lupus anticoagulants. Blood, 70, 69-76.

Rosing, J., van Rijn, J.L.M.L., Bevers, E.M., van Dieijen, G., Comfurius, P. \& Zwaal, R.F.A. (1985) The role of activated human platelets in prothrombin and factor X activation. Blood, 65, 319-332.

Rosing, J., Tans, G., Govers-Riemslag, J.W.P., Zwaal, R.F.A. \& Hemker, H.C. (1983) The role of phospholipids and factor Va in the prothrombinase complex. Journal of Biological Chemistry, 258, $3637-3644$.

Schleider, M.A., Nechman, R.L., Jaffe, E.A. \& Coleman, M. (1976)
A clinical study of the lupus anticoagulant. Blood, 48, 499509.

Tan, E.M., Cohen, A.S., Fries, J.F., Masi, A.T., McShane, J., Rothfield, N.F., Green, R., Schaller, J., Tabal, N. \& Winchester, R.J. (1982) The 1982 revised criteria for the classification of SLE. Arthritis and Rheumatism, 25, 1271-1277.

Thiagarajan, P., Pengo, V. \& Shapiro, S.S. (1986) The use of the dilute Russel viper venom time for the diagnosis of lupus anticoagulants. Blood, 68, 869-874.

Thiagarajan, P., Shapiro, S.S. \& De Marco, L. (1980) Monoclonal immunoglobulin inhibitor with phospholipid specificity. Mechanism of a lupus anticoagulant. Journal of Clinical Investigation, 66, 397-405.

Triplett, D.A., Brandt, J.T., Kaczor, D. \& Schaeffer, J. (1983) Laboratory diagnosis of lupus inhibitors: a comparison of the tissue thromboplastin inhibition procedure with a new platelet neutralization procedure. American Journal of Clinical Pathology, 79, 678682. 